\title{
A Trialectical Cusp: between the real and the represented
}

At the bus stop in SPID Theatre Company's 23176

Katie Beswick, University of Exeter

\section{Introduction: Trialectics, Theatre, Space and Site}

In his seminal book Thirdspace: Journeys to Los Angeles and other real and imagined spaces (1996), Edward Soja 'appropriates' Henri Lefebvre's central argument in The Production of Space (1991), proposing that conventional dialectic analyses are often reductive, falling victim to what he describes as 'the lure of binarism' (Soja 1996: 53-60). Soja suggests that Lefebvre's triadic model usefully 'recomposes the dialectic' through a process he calls 'Thirding-as-Othering', where a 'third' element serves as an 'intrusive disruption that explicitly spatializes dialectical reasoning' (61). This 'trialectical' approach to spatiality emphasises the ceaseless interplay between the perceived, conceived and lived elements of space which, Lefebvre argues, make up our spatial experience of the world (1991).

In the first half of the twentieth century, the dominant paradigms of cultural analysis were historical and sociological: space was outside of this ontological dialectic. The 'trialectic' of perceived, conceived and lived space enables a 'breaking open' of the dialectical dualism that had tended to structure Western philosophy and criticism - in which 'historicality' and 'sociality' were prioritised (Soja 1996: 70-74) - up until the 'spatial turn' of the mid twentieth century (Wharf and Arias 2009: 2-5). A 'Trialectic of Being', Soja argues, must include a consideration of space alongside history and society (71). Soja's extension of Lefebvre's work, amongst other things, draws attention to the ways in which a 'trialectical' conception of space allows for an 'ontological re-structuring' - whereby the spatial conditions of our 'being-in-the-world' are explored and emphasised in order to access an epistemological understanding of the relationship between social, historical and spatial conditions (Soja 1996: 72-73). As Nadine Holdsworth has noted, Lefebvre 'explores how spaces are never empty but always loaded with active meanings produced and re-circulated through dynamic 
social practices' (2007: 296). In Soja's (and Lefebvre's) paradigm-shift our 'existential spatiality' is emphasised.

Theatre is a spatial medium, and, in recent decades, theatre scholars and practitioners have begun to reconceptualise spatial relations in a variety of ways, attempting to shift audience expectations, engender sociality and structure complex shifts in perception. Companies such as Wrights and Sites, Punchdrunk, De La Guarda and Slung Low use site in an attempt to mediate audience experience of space. For example, Wrights and Sites produce a series of 'Mis-Guides' - maps and books that encourage individual or groups of 'walkers' to explore 'towns, cities and landscapes' through a series of 'fictional, fanciful, fragile and personal' encounters (Wrights and Sites 2011). These guides suggest ways that the sites might be navigated; they attempt to foster a playful engagement between participant and space that might enable the participant to interact with a familiar space in a new manner. Punchdrunk's The Masque of the Red Death (2007) is another example of the crystallising of the shift towards spatiality in performance practice. In this immersive performance, Punchdrunk moved outside of the two designated performance spaces of the Battersea Arts Centre (BAC) and took over the entire building. The company used abandoned spaces within the venue that had previously been inaccessible to the public and created installations that the audience were at liberty to move through freely. The performance created an experience that challenged both audience and establishment perceptions of the theatre space. As a result of the performance, the BAC subsequently reconfigured their building to encourage artists to utilise the space more fully (see Punchdrunk 2013).

The 'spatial turn' in performance theory, meanwhile, has included a focus on framing spatial practices within a 'site-specific' model (see Pearson and Shanks 2001, Pearson 2010, Birch and Tompkins 2012, Hunter 2015). Such theoretical work is commonly concerned with those performances taking place in sites for which they have been specially designed, often outside of the traditional theatre building. The uncovering of texture, of the layered 'palimpsest' (Turner in Hunter 2009: 370) of lived experience in specific locations, has become an important part of the way that the sites and spaces of contemporary performance are understood and analysed in theatre and performance scholarship. However, as I discuss in more detail below, despite the necessary attention to spatiality fostered through site-specific peformance theory, there has often been a lack of attention 
to the broader political conditions of site-specific and site-sensitive performance works, which limits the scope of their analysis.

In the remainder of this article I consider Soja's concept of the trialectic as a method for destabilising dominant conceptions of space in performance theory and beyond. I propose that trialectical analysis might usefully foreground connections between 'like sites' in a way that adds a necessary political bent to site-focussed performance analysis. I discuss how SPID Theatre Company's council estate location imbues their work with an inherent politics. Finally, I apply 'trialectics' as an analytical method with which to explore the relationship between the real, the imagined and the represented in SPID Theatre Company's 2008 production 23176, using a trialectic model to expand Kate Katafiaz's (2012) conception of the 'dialectical cusp'. This production took place in the community rooms of the Kensal House estate in Ladbroke Grove, London. The central feature of the set was hyper-realistic depiction of a transport for London bus stop, which referenced similar bus stops just outside the Kensal, and across London. I argue that the fictional bus stop worked affectively to place viewers on a trialectical 'cusp', which disrupted stereotypical depictions of young council estate residents as criminal and delinquent.

\section{Thirdspace and Politics}

As Lefebvre argues, capitalist societies have long used space to create and sustain hegemonic structures of knowledge and power, through which particular people and groups are marginalised (Lefebvre 1991: 10-11). Soja uses the work of bell hooks (1990) to highlight how understanding society via the spatial experiences of the marginalised allows challenges to hegemony; he argues that hooks' work allows 'possibilities for a new cultural politics of difference and identity that is both radically postmodern and consciously spatialized from the beginning' (Soja 1996: 96). With hooks' 'radical postmodernity' as a point of departure, Soja expands Lefebvre's notion of lived space, offering the 'Thirdspace' as an alternative frame through which to consider possibilities for the role of spatiality. Soja proposes his Thirdspace as a development of Lefebvre's spatial trialectic. Drawing on Jorge Luis Borge's short story The Aleph (1971) in which the author presents a limitless space, unbounded by time, he conjures his vision for the Thirdspace:

Thirdspace: the space where all places are one, capable of being seen from every 
angle, each standing clear; but also a secret and conjectured object, filled with illusions and allusions, a space that is common to all of us yet never able to be completely seen and understood, an 'unimaginable universe', or as Lefebvre would put it, 'the most general of products'.

(Soja: 1996: 56)

Soja's deliberately ambiguous definition evokes the complexity of spatial experience and acknowledges his reading of Lefebvre's work: that any articulation of space can only be an 'approximation' of a thing which is infinitely complex and intangible. Soja proposes that an engagement with Thirdspace necessitates a 'praxis', a 'translation of knowledge into action in a consciously - and consciously spatial - effort to improve the world in some significant way' (1996: 22). Performance practices that foreground site are often both inherently and explicitly political; the impetus to make work that challenges established conventions, that takes place in non-traditional spaces and includes or represents peoples marginalised in one way or another, is often related to a desire to engage in praxis; to make a difference to the world, to bring about change in the way we understand and relate to our environments. Thus it is the 'praxical' element of Soja's model that makes it a useful tool for the analysis of performance in contested and non-traditional spaces - he provides a method with which to explore the conditions that structure the life experience of the subaltern 'Other' through a close engagement with marginalised sites and spaces.

Despite the inherently political nature of much site and space focused performance practice, site-specific performance analysis has tended to sideline politics in favour of a focus on the corporeal and material conditions of performance works. As Joanne Tompkins suggests in the introduction to her recent collection exploring site-specific performance, site, as a facet of the wider social space, is inherently political. She notes that politics might be usefully enhanced 'through the generation and performance of site-specific work' (3) and importantly suggests that the critique of such work might operate politically, contributing to 'the articulation of cultural activity as crucial to social well-being' (4).

In site-specific scholarship, where there is often a concern with the dialectical interaction between the human body and individual performance spaces, or the socio-historical conditions of specific sites, the nature of what will be referred to here as 'generic place' has sometimes been ignored. Even in site-specific analyses which usefully foreground the 
political context of performance works, the failure to explicitly articulate how the sociopolitical context of this site might implicate other 'like sites' often limits the scope of the analysis. For example, in Louise Owen's (2012) chapter exploring the site-specific event The Margate Exodus, Owen offers an in-depth reflection on the social and political context of Margate, a British seaside resort, and analyses the work in relation to this context. Although Owen does make connections between this site and broader 'social, economic and political processes' (Kwon in Owen 2012: 151), she does not look beyond the specific site of the work to consider how the conditions of this site might contribute to conditions beyond the immediate location, and feed into the conditions of other, similar spaces. Jerri Daboo suggests that in order to understand the way space and place structures identity, scholars must recognise connections between multiple sites, including sites that are, 'geographical, physiological, cultural, imaginary, theoretical and political' (Daboo 2007: 56). Daboo proposes that the site 'operates on many levels' and that these multiple sites can be considered as 'specific'. She argues that

[t]he importance of the specific site of a particular community not only geographically, but also socially and politically, is vital [...] in order to understand the positioning of [a] community in relation to the formation of knowledge and personal empowerment.

(Daboo 2007: 57)

Daboo proposes that, particularly for theatre makers concerned with socially engaged work,

the idea of site and place needs to be reconfigured and remapped to be seen instead as multiple sites in shifting locations, rather than being a singular 'fixed position', and [to comprehend] how this understanding of site and place relates to a sense of personal identity which is also shifting and in process, rather than fixed.

(Daboo 2007: 55)

Soja's 'Thirdspace' offers a method for theatre scholars to move towards a more explicitly political reading of site-based performance practices. As I illustrate below, a trialectic analysis - which involves deliberately adding a 'third' element to the examination of spatial practices - enables us to more fully articulate the complex ways in which performance practices work politically, on and through site.

\section{'Like Sites'/ ‘Generic Places': SPID Theatre Company’s Council Estate Context}


$\underline{23176}$ was a devised performance work performed and produced by the Specifically Produced Innovatively Directed (SPID) Theatre Company with 13-19 year olds living on the Kensal House estate in Ladbroke Grove, West London. The show was developed during a series of workshops, which were free to participants and took place over a six-month period throughout 2008. 23176 was performed in 2008 and 2009 in the community rooms on the Kensal; in 2010 it was re-worked and performed again under the title The Passerby.

SPID are permanently based on the Kensal House estate, a large social housing estate - or 'council estate' - built in the modernist style, and much of the company's work reflects this socially embedded context. SPID often describes its practice as 'site-specific', reflecting the ways in which performances are authored and the relationship the work fosters between the audience, the site and the wider spatial conditions of the Kensal House estate itself which includes its status as a 'generic' place.

Council estates, as I have argued elsewhere (see Beswick 2015), are 'generic' spaces. At once individual sites with unique, specific features, and, at the same time, imbued with a generic 'estateness', which fixes their identity and connects them to other 'like' estate sites. Initially intended as a stable housing solution for low-income families, council estates have been subject to numerous policy interventions that have led to their decline - both physically and in the public imagination. The 'fixity' of identity commonly attached to the (generic) council estate has contributed to the emergence of these places as contested and contentious sites. Although there has been a long-standing tradition of concern over the lives and lifestyles of those who live on estates (see Ravetz 2001, Hanley 2007), government policies over the past three decades - particularly the Right to Buy, which allowed social renters to buy their properties at a discounted price - have led to more owner occupation and increased distrust of social renters. Changing policies have shaped the way that the (generic) council estate is practiced and perceived, and have contributed to council estates becoming a increasingly complex places. This complexity is compounded by the dominant media discourse where the (generic) estate is often portrayed as a 'dreadful enclosure' (Walter in Damer 1974: 221), which produces its inhabitants, and particularly its social renters, as criminal, delinquent and morally inferior to outsiders.

This generic conception of the council estate works to homogenise and reify these spaces 
and their residents as 'Other' in the British psyche. Although this reified version of the council estate is deeply problematic (see McKenzie 2015 for a discussion of the lived effects of such stigmatization), it is important to acknowledge that the dominant narratives of (generic) estate identity are not necessarily grounded in fiction. Social problems do exist on individual estates where criminal and anti-social behaviour happens (as it does elsewhere). Nonetheless, the causal correlation between the Council Estate and criminality often suggested in representation is reductive, as Bola Agbaje, playwright and author of Council Estate plays Gone too Far (Royal Court 2007), Off the Endz (Royal Court 2010) and Concrete Jungle (Hammersmith 2011) who also works as a housing officer, implied during an interview I carried out with her, as part of a larger project exploring council estate representation:

I manage street properties. And the same social issues on street properties [exist] that people face on estates. There's still issues on streets. I have streets where there's issues of gang culture, there's issues of anti-social behaviour and all that stuff that people associate mainly with estates happens on street properties. So you can't then just say 'it's the area', you have to then look at the wider problem and say okay, what [are] the issues within the family home [...] And 99\% of the time, there are so many different underlying problems that make the kids anti-social.

Agbaje's discussion of her work as a housing officer indicates the intersectional relationship between the council estate resident and narratives of poverty, crime and anti-social behaviour. Her words suggest that the council estate has become an ideological container for issues relating to race (gang culture), class (poverty) and gender (family relationships, single mothers, violence and hyper-masculinity) which are conflated and spatialised in popular representation. I propose that this characterisation creates a phenomenon I will refer to as 'council estateness'- where the term 'council estate' has become a shorthand for social decay and failure.

Pearson and Shank's (2001) definition of site-specificity, which as Tompkins (2012) argues, is widely considered the 'benchmark' for identifying site-specific practices, states that

Site-specific performances [...] rely, for their conception and their interpretation, upon the complex co-existence, superimposition and inpenetration on a number of narratives and architectures, historical and contemporary, of two basic orders: that which is of the site, its fixtures and fittings, and that which is brought to the site, the performance and its scenography: of that which pre-exists the work and that which 
is of the work: of the past and of the present.

(Pearson and Shanks 2001: 23 in Tompkins 2012: 2)

The complex co-existence of the site of performance (the Kensal House estate) and the preexisting conception of the generic council estate environment, which is a social as well as a spatial phenomenon, has particular implications for imbuing 'that which is brought to the site' with meaning in SPID's work. In $\underline{23176}$ the scenography, particularly the recreation of a London bus stop inside the community rooms, which served as a performance venue, enabled the performance to operate in a complex way on the site - shifting the audience between real and fictional worlds and calling the veracity of dominant estate representation into question.

\section{Trialectical Cusp}

Katafiaz proposes that the 'dialectical cusp' is a 'plastic physical point of [de-limitation] which allows the onlooker autonomy, [and] may help figure and understand a lost classical connection between drama and democracy' (2013: 24). In an analysis of Edward Bond's play The Under Room, Katafiaz describes how throughout the performance, the body of an illegal immigrant was dualised; represented by both a dummy and an actor, who are on stage at the same time. She argues that,

In semiotic terms, the dummy is the iconic signifier which visually resembles the human form of the dummy actor to whom it refers; the dummy actor speaks; these words or symbolic signifiers in turn refer back to the dummy.

(Katafiaz 2013: 22)

She proposes that disjuncture between the physical body of the actor and the inanimate body of the dummy work via the gaze of the viewer. She compares the function of dummy/actor to Hans Holbein's painting The Ambassadors - a painting in which the distorted image of a skull in the foreground, if viewed from certain angle, is corrected. She argues that,

Just as we have to shift our gaze to take in first the dummy and then the dummy actor [in the play] when we view Holbein's painting at the National Gallery in London, we have to walk and look at the painting from side-on to see death's head.

(Katafiaz 2013: 24) 


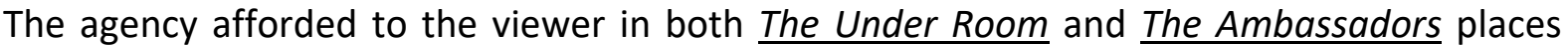
them on a dialectical cusp. Katafiaz proposes that the cusp moves the audience away from binary readings, 'where the adoption of one position bars or excludes the other', and instead positions the viewer on a 'mutable border' where they are afforded 'personal agency' (24). She states that this 'plastic physical point of [de-limitation] which allows the onlooker autonomy, may help figure and understand a lost classical connection between drama and democracy' (Katafiaz 2013: 24). Here, Katafiaz is referring to the ancient Athenian drama, which she argues 'positioned its audience on just such as cusp' (2013: 29),

Theatre mask and the skene, a wooden structure behind the acting space, provided audiences with spaces that incite an active involvement with what is 'behind'. These must have initiated the same urgent physical and intellectual involvement for audiences as Bond's dummy actor [...]. We sit, just as the ancient Athenians did, on a mutable cusp between languages and bodies, between culture and physicality, noticing in the play between them that the two may not 'add up'.

(Katafiaz 2013: 29-30)

Although the spatial practice of $\underline{23176}$ does not implicate the viewers' bodies in a physical movement, as is the case in Katafiaz's examples where crossing the point of delimitation requires a movement of the eyes, they are nonetheless physically positioned on a cusp. This cusp might be more usefully conceptualised trialectical, with a deliberate 'third' element limiting the possibility of reductive readings. This trialectical cusp comprises 1) the boundaries between the practiced space of the 'real' estate and the practiced space of the fictional estate represented in performance, 2) the representations of (generic) estate space that the performance is referencing and 3 ) the imagined space of the (generic) estate that is alive in the minds of the viewers in performance moment, and where the Thirdspace of the performance opens up in a way that might enable audiences to reflexively consider the negative depictions of council estates and their residents.

\section{At the Bus Stop}

23176 - a title that refers to the number of sexual assaults reported in the UK in 2008 - is a secular reworking of the parable of the Good Samaritan. The play tells the story of a group 
of young people who come across a woman who has been sexually assaulted and offer her support, acting against the expectations of the women on the estate who regard the young people gathering in the communal areas outside as a threatening and potentially violent gang. The play demonstrates how sensational narratives of young people in council estate space are absorbed by residents and non-residents, and how this impacts upon young people living on estates; it offers a space whereby young residents can challenge the dominant media representations of the council estate. As such, the production might be considered both inherently and explicitly political - as a kind of protest through performance, where the participants were able to engage in resistance against the socially constructed discourses that structure their homes and feed into their internally and externally constructed identities. The spatial configuration of the work operated in a complex manner to facilitate resistance against dominant 'estate' narratives.

23176 was performed in a representation of a (generic) estate environment inside the Kensal House community rooms. The performance used the 'real' physical space of the Kensal House estate and stereotypical conceptions of estate space to draw attention to the way negative estate stigma structures the collective identity of estate residents. The stage space included graffiti scrawled on walls that had been painted grey to reference the modernist concrete structure of the (generic) estate. The central stage image was a bus stop, scenographically depicted by a red plastic bus bench and two sheets of panelled glass that recreated the bus shelters common on London streets. Because the performance took place on an estate and because audience members were likely to have had to walk past a similar bus stop to arrive at the venue, $\underline{23176}$ immediately co-opted the 'real' space of Kensal House into the narrative of the performance.

At the start of the play, the young performers loitered at the bus stop. Although they were in school uniform, women on the estate - depicted on a screen in a pre-recorded scene that interrupted the stage action - referred to the young people as a 'gang', and expressed fear at their presence. The use of a teenage gang as a symbol of fear for the adults highlighted that young people often struggle to find an individual identity within a space which is highly politicised and subjected to on- going public discourses that serve to create negative conceptions of inner-city youths - such as the 'hoodie' (Bell 2013). Although it is an obvious statement, it is important to emphasise that the fact the performance took place on the 
estate made the work perceptibly about the specific estate it was set on. That the audience knew the young people representing Estate youths were really estate youths gave the work an additional potency. 23176 depicts a generic Estate environment in an attempt to explore the way that fictional depictions of the Council Estate work to shape the experience of specific estates for residents and visitors.

My own experience and understanding of estate space were called into play in 23176 via the fictional bus stop, and the use of the bus stop throughout the performance. The material qualities of the represented bus stop - for example, the use of an actual Transport for London (TFL) bench, distinctively shaped and red, and the display of TFL posters on the glass - evoked recollections of my own practice of bus stop spaces. As I watched the young people loitering at the fictional bus stop space, dressed in school uniforms, I recalled the experience of being a young person, dressed in school uniform at a bus stop and the experience of travelling on buses as an adult, expecting young people to behave poorly which they rarely did. The fictional frame of the performance along with the 'realistic' material qualities of the bus stop evoked an interaction between the 'real' and the represented, where my sensory and critical engagement with the performance was heightened. I draw attention to my experience to illustrate how 23176 usefully uses the form of the 'real', or the perceived space of Lefebvre's triadic model, to engage audience members, and to highlight that the precise interaction between the viewer and the work depends upon the viewers' habitus (Bourdieu 1977) - the experiences, knowledge and assumptions that they bring to the performance.

That the fictional, stage bus stop referenced a similar bus stop at the boundary of the estate worked to co-opt the 'real', perceived space of the estate into the narrative and to intervene in the habitus of audience members. I propose that the image of the bus stop placed me, as an audience member, on a trialectical 'cusp' (24). It is at this cusp where the viewer is implicated in the performance and where moments for reflexivity and critical engagement are activated.

Bus stops are public spaces most often used by those who do not have means for private travel, or for whom public travel is more convenient. Although public transport is traditionally associated with the poor working classes, in London, because of the high cost 
of driving and parking in the city, people from all walks of life use the bus network. However, public transport is not without its tensions. Hanley (2007) has made the connection between the bus and the (generic) estate. She points to the famous quotation, apocryphally attributed to Margaret Thatcher - 'a man who, beyond the age of 26, finds himself on a bus can count himself as a failure' - to argue that all spaces of public subsidy have been implicated in a negative discourse that seeks to discredit the users of state subsidised-services (14). In London, bus stops are emblematic of the inner-city, and are commonly associated with young people, often with young people who are disruptive and unruly - perhaps because public buses are relatively un-policed and, during the day, often shared by groups of students using them for transport to school and adults commuting to work. The use of the bus stop as a central image, then, as well as positioning the audience in the space between the 'real' and the fictional, introduces subtle relationships between the estate resident and the non-resident public that implicate the wider council estate discourse. The fictional stage bus stop recalls the bus stops on the boundary of the Kensal House estate, but also calls upon the audience's memory of similar bus stops across the city and therefore similar relationships between groups of young people and adults, 'gangs' and local crime and the expectations and behaviours of residents and non-residents in a shared public space.

The structures that secure residents of estates, and indeed residents of other marginalised places, within the dominant discourses of 'lack' (McKenzie 2015) are both physical and mental. Habitus exists in the body of residents and non-residents but also shapes how they see the world. That the bus stop serves as the site where the young people are, early on in the narrative, characterised as a criminal gang and the location where they defy expectation by comforting the woman who has been attacked allows the location to operate as a cusp, where the viewer is afforded the chance to question or disrupt their understanding of the estate and its residents. Within the trialectic that the audience are forced to navigate, the image of the bus stop, as a representation and its reality, places the viewer on an intellectual threshold.

Katafiaz defines dramatic events as

the state of uncertainty we experience when language breaks down, when our expectations are frustrated, as in accidents; these events position us between 
languages and bodies, word and voice, gaze and eye, expectation and lack, where things do not happen as they are supposed to.

(Katafiaz 2013: 32)

The bus stop space in $\underline{23176}$ is a recapitulated dramatic site where 'things do not happen as they are supposed to'. This implicates the audience and opens up moments for them to confront their expectations. Although, as Katafiaz notes the 'politics' of such threshold experiences lie in the 'personal response' of the individual audience members (32). Ultimately, ingrained habitual ways of seeing the world may not be altered by a single performance. Performance can only offer moments for reflexive experience. Drama can prompt an audience - can engage them in a physical and mental process through which they might reconsider how they see the world - but it cannot force change. This is the democracy of drama.

\section{Conclusion}

[...] what may be challenging to one audience/community may be innocuous to another. To say this is simply to stress the ideological relativity of performance, to make the fairly obvious point that the same performance may meet with vastly different reactions in different ideological contexts.

(Kershaw 1992: 33)

SPID's work exemplifies some of the ways in which the coming together of the 'real' and the represented in the lived space of performance provides possibilities for intervention and transformation in spatial production. SPID's practices open up moments for audience reflexivity in the viewing processes and demonstrate the way in which community-based, site-specific theatre might give participants an opportunity to engage in a critical dialogue. This dialogue operates as what Kershaw calls the 'dramaturgy of protest'; $\underline{23176}$ actively resists the status quo and, in the subversion of expectation, organises a visionary narrative that provides an 'entropic resistance of histories shaped by dominant socio-political forces' (Kershaw 1999: 90). The performance operates, then, as a critical resistance against the dominant narratives of the council estate that threaten to subsume residents' identitymaking. Thus, SPID's work has the potential to function as a strategy for resisting dominant socio-political forces. While the performance practice itself does not mirror the public demonstrations - including the fall of the Berlin Wall and Tiananmen Square - Kershaw references in his writing on protest (1999: 89-125), it still involves what we might consider 
'direct' political action in the form of publically confronting narratives of the inner- city constructed by the dominant power-elite. The use of particular strategies within $\underline{23176}$, including the bus stop trialectic, can be read within Kershaw's understanding of the dramaturgy of protest whereby the performance event offers 'a glimpse of the future as pure freedom from the constraints of the real', and where 'the imaginary became more important than the possible, the visionary more persuasive than the rational' (Kershaw 1999: 106). However, because of the clear differences between 23176 and Kershaw's examples of public demonstrations - particularly in the way the 'visionary' is organised, I propose that SPID's work operates as a critical protest (see also Beswick 2011), where grass roots, site-specific performance practice operates to intervene in and interrupt the production of space. In this critical way artistic practice is able to move beyond anarchic protest and attempt to create a sustainable platform for intervention in dominant discourse; operating as a balance between protest and sustainable arts practice.

Philip Taylor uses Augusto Boal's concept of 'metaxis' to describe how a dialogue between the real and represented calls upon the audience to critically participate in the work.

The state of metaxis is achieved when a dialogue occurs between the real and the fictional worlds. As Boal argues, the spectators must not leave 'their brains with their hats upon entering the theatre as do Bourgeois spectators'. The capacity of the spectators to become spect-actors - where they consciously and deliberately reflect and act on the implications of their own and others' actions - is central to an applied theatre.

(Taylor 2003: 5-6)

In confronting the various fragments of the reality of estate space, SPID manage both to offer an alternative reality, and to analyse and question the ways in which Estate space is produced through representation. While there are limitations to the scope and complexity of the discourse that SPID encourage, the work articulates a clear praxis. Taylor proposes that

praxis is powered by an agenda, a desire to push as to reflect on our practices and refine our theoretical languages, a step toward acting on and changing our life circumstances. Put simply, praxis denotes the action, reflection, and transformation of people as they engage with one another. Those involved in praxis can anticipate that such action, reflection, and transformation should help people create a just and better world. 
As Kershaw proposes in the quotation that opens this section, the extent to which any critical practice is able to affect its participants is context reliant - and reliant upon the susceptibility of individuals to a particular message. What I have hoped to demonstrate here is that the critical tools Soja offers to interrogate spatial practices can be usefully applied to tease out the political qualities of site-specific works; a trialectic analysis enables us to widen the remit of site-specific theory beyond the material conditions of the performance towards the praxical nature of the works and understand them more fully in their embedded, political context.

\section{References}

Bell, C. 2013. The Inner City and the 'Hoodie'. Wasafiri. 28(4), pp.38-44.

Beswick, K. (2011). The Council Estate: Representation, Space and the Potential for Performance. Research in Drama Education: The Journal of Applied Theatre and Performance. 16(3), pp.421-435.

Beswick, K. (2015). Ruin Lust and the Council Estate: Nostalgia and Ruin in Arinze Kene's God's Property. Performance Research. 20(3), pp.29-38.

Bourdieu, P. 1977. Outline of a Theory and Practice. Cambridge: Cambridge University Press. Daboo, J. 2007. Unveiled: Interrogating the use of Applied Drama in Multiple and Specific Sites. Research in Drama Education: The Journal of Applied Theatre and Performance. 12(1), pp.55-64.

Damer, S. 1974. Wine Alley: The Sociology of a Dreadful Enclosure. The Sociological Review. 22(2), pp221-248.

Holdsworth, N. 2007. Spaces to Play/Playing with Spaces: Young People, Citizenship and Joan Littlewood. Research in Drama Education: The Journal of Applied Theatre and Performance. 12(3), pp.293-304.

Hunter, V. 2005. Embodying the Site: the Here and Now in Site-Specific Dance Performance. New Theatre Quarterly. 21(4) pp.367-381. 
Hunter, V. 2015. Moving Sites: Investigating Site-Specific Dance Performance. London. Routledge.

Katafiaz, K. 2013. Staging Reality Beyond Representation: A Perplexing Bondian Body. Journal of Contemporary Drama in English. 1(1), pp. 25-33.

Kershaw, B. 1992. The Politics of Performance: Radical Theatre as Cultural Intervention. London: Routledge.

Kershaw, B. 1999. The Radical in Performance: Between Brecht and Baudrillard. London: Routledge.

Hanley, L. 2007. Estates: An Intimate History. London: Granta Books.

hooks, b. 1990. Yearning: Race, Gender, and Cultural Politics. Boston: South End Press.

McKenzie, L. 2015. Getting By: Estates, Class and Culture in Austerity Britain. Bristol: Polity Press.

Kwon, M. 2002. One Place After Another: Site-specific Art and Locational Identity. Cambridge, Massachusetts and London: Massachusetts Institute of Technology Press.

Lefebvre, H. 1991. The Production of Space. Oxford: Basil Blackwell.

Owen, L. 2012. 'Places, Like Property Prices, Go Up and Down': Site-Specificity, Regeneration, and The Margate Exodus. In: Birch, A and Tompkins, J. eds. Performing Sitespecific Theatre: Politics, Place, Practice. Basingstoke: Palgrave MacMillan, pp.150-164.

Pearson, M. and Shanks, M. 2001. Theatre/Archaeology. London and New York: Routledge.

Pearson, M. 2010. Site-specific Performance. Basingstoke: Palgrave Macmillan.

Punchdrunk. 2013. The Masque of the Red Death. [Online]. [Accessed $22^{\text {nd }}$ November 2013]. Available from: http://punchdrunk.com/past-shows/article/the-masque-of-the-red-death

Ravetz, A. 2001. Council Housing and Culture: The History of a Social Experiment. Routledge: Abingdon and New York.

Soja, E. W. 1996. Thirdspace: Journeys to Los Angeles and other Real-and-Imagined Places. Malden: Blackwell. 
Taylor, P. 2003. Applied Theatre: Creating Transformative Encounters in the Community. Portsmouth: Heinemann.

Tompkins, J. 2012. The Place and Practice of Site-Specific Theatre and Performance. In: Birch, A. and Tompkins, J. eds. Performing Site-specific Theatre: Politics, Place, Practice. Basingstoke: Palgrave Macmillan. pp. 1-17.

Turner, C. 2004. Palimpsest or Potential Space? Finding a Vocabulary for Site-specific Performance. New Theatre Quarterly. 20(4), pp. 373 -390.

Wrights and Sites. 2011. Mis-Guide. [Online]. [Accessed 22 ${ }^{\text {nd }}$ November 2013]. Available from: http://www.mis-guide.com/mg.html

Wharf, B. and Arias, S. eds. 2009. The Spatial Turn: Interdisciplinary Perspectives. London and New York: Routledge. 